\title{
PERSEPSI PETANI DAN ADAPTASI BUDIDAYA TEMBAKAU-SAYURAN ATAS FENOMENA PERUBAHAN IKLIM DI DESA TLOGOLELE, KECAMATAN SELO, KABUPATEN BOYOLALI (Farmers Perception and Adaptation of Tobacco-Vegetables Cultivation toward Climate Change Phenomena at Tlogolele Village, Selo Sub District, Boyolali Regency)
}

\author{
Suprihati* ${ }^{*}$ Yuliawati, Hartati Soetjipto dan Teguh Wahyono \\ Universitas Kristen Satya Wacana, Jln Diponegoro 52-60, \\ Salatiga, Indonesia, 50711.
}

*Penulis korespondensi. Tel: 081326047437. Email: suprihati@staff.uksw.edu.

\author{
Diterima: 17 April 2015
}

Disetujui: 23 Juni 2015

\begin{abstract}
Abstrak
Masyarakat Desa Tlogolele, Kecamatan Selo, Kabupaten Boyolali mengandalkan pendapatan dari budidaya tembakau dan sayuran yang keduanya sangat rentan terhadap perubahan iklim. Kesiapan petani untuk memahami dampak negatif perubahan iklim dan bagaimana upaya untuk beradaptasi terhadap perubahan tersebut sangat menentukan keberhasilan petani bertahan dan secara terus-menerus mengembangkan pertaniannya. Tujuan penelitian adalah mengkaji persepsi petani terhadap perubahan iklim dan menganalisis adaptasi yang dilaksanakan oleh petani. Pengambilan sampel secara purposive, yaitu petani tembakau-sayuran, sebanyak 50 orang. Pengumpulan data dilakukan dengan metode survei melalui wawancara dengan kuesioner terstruktur, observasi dan diskusi terfokus. Keakuratan data persepsi petani atas fenomena perubahan iklim dibandingkan dengan data tren perubahan iklim yang tercatat di stasiun klimatologi terdekat bersumber dari Badan Meteorologi Klimatologi dan Geofisika (BMKG) Semarang. Data hasil penelitian dianalisis secara deskriptif. Hasil penelitian menunjukkan bahwa petani mengetahui isu perubahan iklim dan merasakan pengaruhnya terhadap kegiatan budidaya pertanian terutama masalah kekeringan dan serangan organisme pengganggu tanaman. Petani meresponnya melalui adaptasi kegiatan pemilihan jenis tanaman, waktu tanam, cara mengolah tanah, dan pemberian pupuk.
\end{abstract}

Kata kunci: adaptasi budidaya, perubahan iklim, persepsi petani, tembakau, sayuran.

\begin{abstract}
The farmers at Tlogolele village-Selo, Boyolali, obtain their main income from tobacco and vegetables production; both are highly vulnerable to climate change. Farmers' readiness to understand the negative impact of climate change and how to adapt their cropping system determine their success to survive on sustainable agriculture. The purposes of this study were to evaluate the farmers' perception on climate change and analyze their adaptation strategy. Samples were taken purposively, consist of 50 tobacco-vegetable farmers. Data were collected by survey method through interviewing by using structured questionnaires, observation and focus group discussion. The accuracy of farmers' perceptions on climate change was compared with the data of climate change trends recorded in the nearest climatological station in Semarang (BMKG). Data were analyzed descriptively. The results show farmers were aware of the climate change issues and their impacts on farming activities; especially for the problem of drought and pest attacks. Farmers adapted by selecting crops type, managing planting time and land accordingly as well as applying fertilizers.
\end{abstract}

Keywords: adaptation of cultivation, climate change, farmers' perception, tobacco, vegetables.

\section{PENDAHULUAN}

Perubahan iklim yang sedang terjadi berikut segala dampaknya termasuk pada bidang pertanian tidak dapat dihindari. Di beberapa wilayah di Indonesia gejala perubahan iklim telah dirasakan, di antaranya musim kemarau yang berlangsung dari tahun ke tahun semakin panjang, dan musim penghujan dengan intensitas yang lebih tinggi, tetapi waktunya lebih singkat serta bergeser dari waktu yang biasanya (Naylor dkk., 2007). Akibatnya, para petani tidak mampu memprediksi musim tanam secara akurat, termasuk menggunakan pengetahuan lokal dalam memprediksi musim (Melviana dkk., 2007).

Persepsi merupakan proses pemberian arti terhadap lingkungan oleh individu. Oleh karena itu, setiap individu memberikan arti terhadap stimulus secara berbeda meskipun obyeknya sama. Cara individu melihat situasi seringkali lebih penting daripada situasi itu sendiri (Gibson dkk., 1997). Pemahaman terhadap persepsi petani tentang perubahan iklim sangat penting karena persepsi tersebut membentuk kesiapan petani untuk 
melakukan adaptasi dan penyesuaian-penyesuaian teknik budidayanya. Hasil penelitian di India yang dilakukan oleh Dhaka dkk. (2010) menunjukkan bahwa usia, pengalaman bertani, inovasi, kesadaran lingkungan dan eksposur media massa memiliki hubungan yang positif dan signifikan dengan persepsi petani terhadap perubahan iklim.

Adaptasi merupakan salah satu pilihan kebijakan untuk mengurangi dampak negatif perubahan iklim (Owombo dkk., 2014). Tanpa adaptasi, perubahan iklim akan merugikan sektor pertanian, tetapi dengan adaptasi, kerentanan dapat berkurang secara signifikan (Gbetibouo, 2008). Adaptasi terhadap perubahan iklim mengacu pada penyesuaian dalam sistem alam atau manusia sebagai respon terhadap rangsangan iklim aktual atau yang diperkirakan dari efek perubahan iklim yang secara nyata merugikan atau berpeluang menguntungkan (Anonim, 2001). Adaptasi perubahan iklim juga dapat diartikan sebagai bentuk respons penyesuaian yang dilakukan untuk mengatasi dampak perubahan iklim (Anonim, 2012). Dalam sektor pertanian hal ini antara lain bisa dilakukan dengan cara pemanfaatan informasi mengenai suhu dan curah hujan dalam menentukan waktu tanam dan menentukan jenis tanaman yang sesuai, mempergunakan bibit yang toleran (misalnya terhadap kadar garam tinggi, tingkat ketersediaan air), menggunakan cara pengolahan lahan yang lebih baik, dan lain-lain.

Hasil penelitian Kurniawati (2012) terhadap 100 petani sayuran di desa Cibodas menunjukkan adaptasi petani terhadap perubahan iklim dilakukan dengan mengubah teknik pengolahan tanah (93\%), mengubah teknik pengairan dan drainase (64\%), mengubah teknik pengendalian OPT (53\%), mengubah pola tanam (23\%), dan menggeser waktu tanam (13\%). Selanjutnya hasil penelitian serupa terhadap 500 petani di salah satu distrik India dilaporkan Dhaka, dkk. (2010), menunjukkan sistem pertanian terintegrasi merupakan salah satu strategi yang terbanyak (84,6\%) dilakukan petani dalam menanggapi perubahan iklim, selain melakukan rotasi tanaman (74,8\%), tumpang sari (72,4\%), perubahan waktu tanam $(71,2 \%)$, memilih varietas tanaman yang toleran terhadap kekeringan (62,4\%). Hasil analisis regresi logistik menunjukkan bahwa faktor pendidikan dan keterampilan bertani berpengaruh signifikan terhadap peluang keputusan petani dalam beradaptasi terhadap perubahan iklim (Kurniawati, 2012)

Masyarakat desa Tlogolele, mengandalkan pendapatan dari budidaya tembakau dan sayuran yang keduanya sangat rentan terhadap perubahan iklim. Kesiapan petani untuk menyadari ataupun memahami dampak negatif perubahan iklim dan bagaimana upaya untuk beradaptasi terhadap perubahan tersebut sangat menentukan keberhasilan petani agar mampu bertahan dan secara terusmenerus mengembangkan pertaniannya. Oleh karena itu, harus dilakukan upaya adaptasi, yaitu mempersiapkan diri dan hidup dengan berbagai perubahan akibat perubahan iklim, baik yang telah terjadi maupun mengantisipasi dampak yang mungkin terjadi. Berdasarkan latar belakang tersebut, tulisan ini bertujuan untuk mengkaji persepsi petani terhadap perubahan iklim dan menganalisis upaya adaptasi yang dilaksanakan oleh petani.

\section{METODE PENELITIAN}

Penelitian ini dilaksanakan di desa Tlogolele kecamatan Selo, kabupaten Boyolali pada bulan April - Oktober 2013. Lokasi penelitian ditentukan secara purposive, dengan beberapa pertimbangan. Pertimbangan pertama bahwa desa Tlogolele merupakan desa dengan tingkat rawan bencana tertinggi di kecamatan Selo yang sangat rentan terhadap bencana siklus (erupsi gunung) dan bencana lainnya yang disebabkan oleh perubahan iklim. Pertimbangan lain adalah sebagian besar penduduknya bermata pencaharian sebagai petani sayuran. Jenis sayuran yang dibudidayakan dan menjadi andalan petani meliputi bawang daun, wortel, kubis, sawi, cabe, tomat, buncis, mentimun. Jenis tanaman perkebunan utama yang diusahakan adalah tembakau.

Pengambilan sampel dilakukan dengan metode non probability sampling secara purposive, yaitu hanya petani yang melakukan budidaya tembakausayuran yang dijadikan sampel. Sampel diambil sebanyak 50 orang petani dari total seluruh petani di Desa Tlogolele.

Pengumpulan data dilakukan dengan metode survai. Pengambilan data persepsi dan upaya adaptasi dilakukan melalui wawancara dengan menggunakan kuesioner terstruktur, observasi dengan melakukan pencatatan dan pengamatan secara langsung tentang praktek budidaya tembakau-sayuran dan adaptasi petani terhadap perubahan iklim, dan diskusi terfokus (Focus Group Discussion). Keakuratan data persepsi petani atas fenomena perubahan iklim dibandingkan dengan data tren perubahan iklim (suhu rata-rata bulanan dan curah hujan bulanan) selama rentang tahun 2006 sampai 2014 yang tercatat di stasiun klimatologi terdekat (kecamatan Ngemplak dan Selo, kabupaten Boyolali) bersumber dari Badan Meteorologi Klimatologi dan Geofisika Semarang. Data hasil penelitian dianalisis secara deskriptif. 


\section{HASIL DAN PEMBAHASAN}

\section{Pengetahuan Petani tentang Fenomena Perubahan Iklim}

Petani telah mengetahui adanya perubahan kondisi iklim mikro di Desa Tlogolele yang berdampak pada penurunan kualitas dan kuantitas panen, bahkan ada yang mengalami kegagalan panen sehingga menyebabkan kerugian. Semua responden petani di Desa Tlogolele mengetahui dan mempunyai perhitungan cuaca/iklim yang bersumber dari kebiasaan lokal. Pada saat ini, pengetahuan lokal tersebut masih dipraktekkan/dijalankan oleh $36 \%$ responden, sisanya (64\%) tidak menjalankan. Selain itu sebagian besar responden (98\%) mengetahui tentang fenomena perubahan iklim, meskipun tidak dapat menjelaskan arti perubahan iklim. Hal ini menunjukkan tingkat pengetahuan petani yang rendah mengenai isu perubahan iklim yang sedang terjadi saat ini. Sekitar 58\% responden menyatakan bahwa mereka mendapatkan informasi tentang perubahan iklim dari petugas desa/penyuluh pertanian/petugas lapang, pelatihan (18\%), dari sekolah lapang (2\%) dan sisanya (22\%) tidak menjawab.

Pada umumnya responden di desa Tlogolele telah mengetahui adanya perubahan pada beberapa komponen iklim yang biasa digunakan untuk mengukur perubahan iklim (Tabel 1). Berdasarkan Tabel 1, dalam hal pergeseran musim hujan dan

Tabel 1. Pengetahuan responden mengenai perubahan yang terjadi pada komponen iklim di Desa Tlogolele.

\begin{tabular}{lrr}
\hline \multirow{2}{*}{ Komponen iklim } & \multicolumn{2}{c}{ Persentase (\%) } \\
\cline { 2 - 3 } & \multicolumn{1}{c}{ Ya } & Tidak \\
\hline Pergeseran musim hujan dan kemarau & 94 & 6 \\
Curah hujan makin tinggi & 94 & 6 \\
Peningkatan suhu udara & 92 & 8 \\
Angin bertambah kencang & 2 & 98 \\
Cuaca ekstrim & 76 & 24 \\
\hline
\end{tabular}

Sumber: Data primer 2013. kemarau, 94\% petani menyatakan bahwa musim hujan lebih panjang dari musim kemarau, sisanya menyatakan sebaliknya. Sekitar $94 \%$ petani merasakan curah hujan yang tinggi dan intensitas hujan yang rendah, 92\% petani melaporkan suhu udara terasa lebih panas, $76 \%$ petani menyatakan angin bertiup lebih lamban, 22\% petani menyatakan tidak ada perubahan angin dan hanya $2 \%$ petani yang menyatakan angin bertiup lebih kencang. Sekitar $76 \%$ petani merasakan cuaca ekstrim, berupa kekeringan (60\%), longsor (6\%) dan banjir (2\%). Penelusuran lebih lanjut, sekitar 96\% petani melaporkan perubahan iklim mulai dirasakan tiga sampai empat tahun terakhir, 4\% petani sudah merasakan sejak enam sampai tujuh tahun terakhir.

\section{Pergeseran Musim Hujan dan Kemarau}

Temuan persepsi petani mengenai pergeseran musim hujan dan kemarau dikonfirmasi dengan pengolahan data curah hujan selama sembilan tahun terakhir (2006-2014). Berdasarkan klasifikasi bulan basah, lembab dan kering terlihat variasi curah hujan tahunan di Desa Tlogolele tidak menggeser pola sebaran musim secara signifikan (Tabel 2)

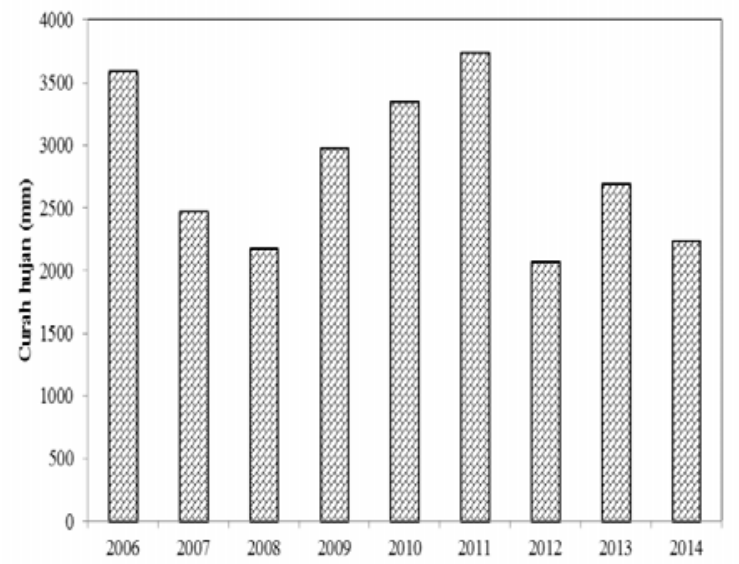

Gambar 1. Variasi curah hujan tahunan di desa Tlogolele (Sumber: Data BMKG 2015-diolah).

Tabel 2. Distribusi bulan basah, lembab dan kering di desa Tlogolele.

\begin{tabular}{lllllllllllll}
\hline Tahun & Jan & Feb & Mar & Apr & Mei & Juni & Juli & Agt & Sept & Okt & Nop & Des \\
\hline 2006 & BB & BB & BB & BB & BB & BK & BK & BK & BK & BK & BB & BB \\
2007 & BB & BB & BB & BB & BL & BK & BL & BK & BK & BK & BB & BB \\
2008 & BB & BB & BB & BB & BK & BK & BK & BK & BK & BB & BB & BB \\
2009 & BB & BB & BB & BL & BB & BK & BK & BK & BK & BB & BB & BB \\
2010 & BB & BB & BB & BB & BB & BL & BK & BB & BB & BB & BL & BB \\
2011 & BB & BB & BB & BB & BB & BK & BL & BK & BK & BB & BB & BB \\
2012 & BB & BB & BB & BB & BB & BK & BK & BK & BK & BL & BB & BB \\
2013 & BB & BB & BB & BB & BB & BB & BK & BK & BK & BB & BB & BB \\
2014 & BB & BB & BB & BB & BB & BK & BK & BK & BK & BK & BB & BB \\
\hline
\end{tabular}

Sumber: Data BMKG, 2015 (diolah). Keterangan:

$\mathrm{BB}=$ Bulan basah, jika curah hujan $>100 \mathrm{~mm} /$ bulan

$\mathrm{BL}=$ Bulan lembab, jika curah hujan 60-100 mm/bulan

$\mathrm{BK}=$ Bulan kering, jika curah hujan $<60 \mathrm{~mm} /$ bulan 


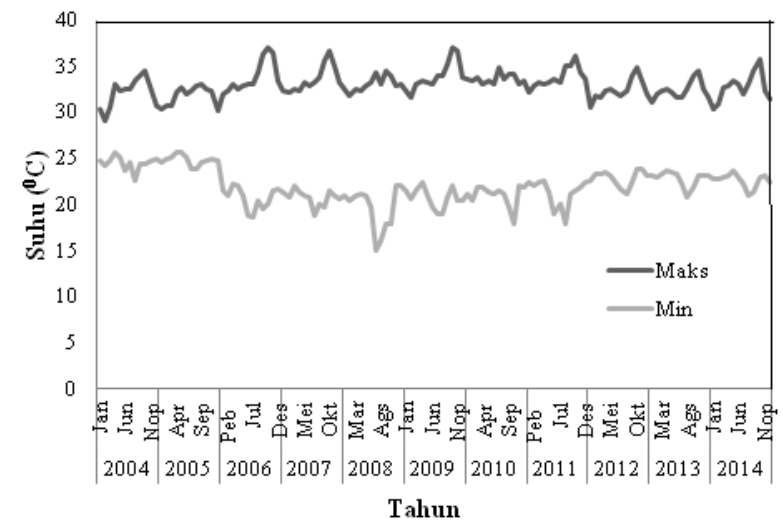

Gambar 2. Perubahan suhu maksimum dan minimum di desa Tlogolele (Sumber: Data BMKG 2015-diolah).

\section{Curah hujan makin tinggi}

Temuan persepsi petani mengenai curah hujan yang dirasakan semakin tinggi dikonfirmasi dengan data curah hujan tahunan (Gambar 1). Gambar 1 menunjukkan variasi curah hujan tahunan yang cukup mencolok, dicirikan dengan curah hujan tahunan yang sangat tinggi pada tahun 2006 dan 2010-2011, curah hujan sedang pada tahun 2007, 2009, dan 2013, serta curah hujan relatif rendah pada tahun 2008, 2012 dan 2014.

\section{Peningkatan suhu udara}

Hasil olahan atas data suhu di desa Tlogolele rentang tahun 2004-2012 menunjukkan hal yang menarik yaitu tren peningkatan suhu maksimum dan tren penurunan suhu minimum. Hal ini menunjukkan peningkatan amplitude suhu seiring dengan waktu (Gambar 2).

\section{Persepsi Petani atas Perubahan Iklim dan Fluktuasi Produksi}

Pemahaman responden atas fenomena perubahan iklim mempengaruhi persepsi akan dampak perubahan iklim terhadap kegiatan bercocok tanam yang dirasakan petani pada kontinuitas ketersediaan air dan masalah organisme pengganggu tanaman/OPT (Tabel 3). Perubahan iklim mikro di lahan pertanian juga ditengarai berdampak pada jenis dan tingkat serangan OPT. Permasalahan OPT di Desa Tlogolele akibat perubahan iklim menjadi bagian dari permasalahan global. Kocmankova dkk. (2014) melaporkan peningkatan kejadian dan aktivitas serangan organisme membahayakan di Chekoslowakia akibat perubahan iklim. Demikian juga Karuppaiah dan Sujayanad (2012) menunjukkan peningkatan dinamika populasi hama pada tanaman padi di India, sehingga perubahan iklim mempengaruhi strategi pengelolaan OPT di California (Trumble
Tabel 3. Persepsi responden terhadap pengaruh perubahan iklim atas kegiatan pertanian.

\begin{tabular}{lc}
\hline $\begin{array}{l}\text { Persepsi pengaruh perubahan iklim } \\
\text { atas kegiatan pertanian }\end{array}$ & responden \\
\hline $\begin{array}{l}\text { Pertimbangan faktor cuaca dalam } \\
\text { kegiatan pertaniannya }\end{array}$ & 70 \\
$\begin{array}{l}\text { Kondisi iklim saat ini mempengaruhi } \\
\text { ketersediaan air untuk pertanian }\end{array}$ & 98 \\
$\begin{array}{l}\text { Kondisi iklim saat ini mempengaruhi } \\
\text { jenis dan tingkat serangan OPT }\end{array}$ & 96 \\
\hline Sumber: Data primer, 2013.
\end{tabular}

Sumber: Data primer, 2013.

Tabel 4. Persepsi responden atas penyebab fluktuasi produksi.

\begin{tabular}{lc}
\hline Penyebab fluktuasi produksi & $\begin{array}{c}\text { \% Jawaban } \\
\text { responden }\end{array}$ \\
\hline Perubahan iklim/cuaca & 100 \\
Kekeringan & 100 \\
Erupsi gunung Merapi & 98 \\
Serangan HPT/OPT & 90 \\
Sistem irigasi tidak ada & 98 \\
Perhatian petani yang kurang & 98 \\
\hline Sumber: Data primer, 2013.
\end{tabular}

dan Butler, 2009) maupun di India (Fand dkk., 2012).

Perilaku hujan mempengaruhi simpanan air bumi di daerah hulu sebagai penyedia air bagi masyarakat di sekitarnya. Perpaduan peningkatan penguapan air oleh peningkatan suhu dan penyusutan ketersediaan air dirasakan oleh petani sebagai bencana kekeringan.

Paparan berikut diharapkan dapat menggambarkan faktor penyebab serta terumuskannya akar permasalahan utama fluktuasi produksi pertanian. Menurut persepsi responden fluktuasi produksi terutama disebabkan oleh perubahan iklim/cuaca, kekeringan, erupsi gunung Merapi, keberadaan serangan hama penyakit tanaman/OPT, tidak adanya sistem irigasi dan perhatian petani yang kurang (Tabel 4).

Tabel 4 mengindikasikan masalah kesiapan dan kesigapan petani atas gejala alam yang diwujudkan melalui pengelolaan lahan. Ketersediaan sistem informasi baik iklim maupun bencana dari daerah lereng gunung berapi aktif sangat membantu. Penyiapan masyarakat baik melalui pembacaan tanda alam maupun kemasan teknologi berperan penting dalam memadukan mitos dengan teknos. Wahyono dan Subanar (2012) mengembangkan Rancang Bangun Sistem "Permadi": Peringatan Dini Serangan Hama Tanaman Padi Berbasis Data Historis Klimatologi yang dengan modifikasi tertentu dapat diterapkan pada tanaman tembakau-sayuran

Untuk mengatasi fluktuasi produksi, seluruh responden pada umumnya menerapkan pengelolaan iklim mikro dengan pemakaian mulsa plastik (Gambar 3). Pemakaian mulsa plastik memiliki 


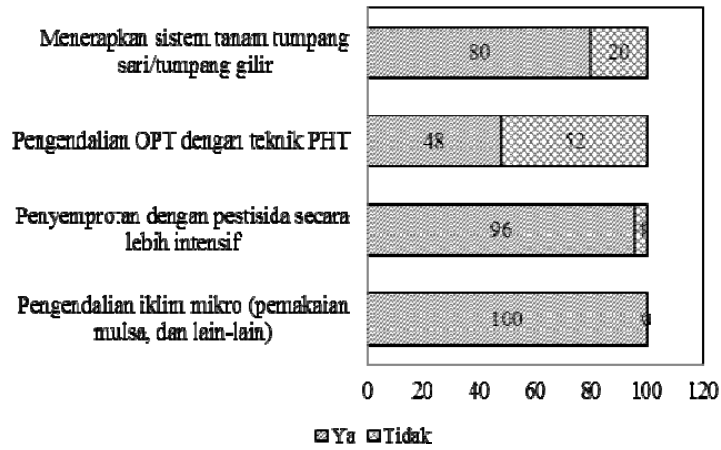

Gambar 3. Diagram upaya petani mengatasi fluktuasi produksi di Desa Tlogolele.

banyak keunggulan yaitu mengurangi evaporasi air tanah, mengurangi fluktuasi suhu, menekan pertumbuhan gulma sehingga mengurangi tenaga kerja untuk penyiangan. Sejalan dengan hasil penelitian Nurmas dan Fitriah (2011) yang menyatakan peningkatan hasil bayam merah maupun Suwignyo dkk. (2012) peningkatan persentase tanaman berbunga dan hasil jagung pada tanah berpasir meningkat akibat pemberian mulsa plastik. Dampak langsung dari penutupan mulsa ini adalah sangat terbatasnya bidang resapan air, sehingga cukup banyak air hujan yang tidak terinfiltrasi ke dalam tanah namun mengalir sebagai aliran permukaan. Mengacu kearifan lokal Desa Tlogolele, tanaman paitan/crobo (Tithonia diversifolia) juga potensial dimanfaatkan sebagai mulsa selaras dengan hasil penelitian Agbede dkk. (2013) di Afrika Barat. Dengan tekstur tanah berpasir, laju infiltrasi dapat ditingkatkan sekaligus mengurangi aliran permukaan dengan penerapan teknik rorak (blumbang).

Sejalan dengan hasil penelitian Kurniawati (2012) terhadap petani sayuran di Cibodas, penyemprotan pestisida secara lebih intensif menjadi pilihan utama petani di desa Tlogolele dalam pengendalian OPT dan baru 48\% responden yang menerapkan pengendalian OPT dengan teknik Pengendalian Hama Terpadu (PHT). Pemanfaatan materi lokal sebagai pestisida nabati sebagai bagian Low External Input for Sustainable Agriculture (LEISA) dapat lebih ditingkatkan.

Mengurangi risiko fluktuasi produksi melalui penerapan sistem tumpang sari dilaksanakan oleh 80\% responden. Strategi ini sejalan dengan hasil penelitian Dhaka dkk. (2010) di sebuah distrik India. Penerapan sistem tumpang sari juga berkaitan dengan efisiensi pemanfaatan lahan dan keseimbangan neraca hara.

\section{Persepsi dan Adaptasi Budidaya atas Fenomena Perubahan Iklim}

Persepsi petani atas fenomena perubahan iklim, seperti pergeseran musim, peningkatan curah
Tabel 5. Adaptasi budidaya tanaman atas perubahan iklim yang dilakukan petani.

\begin{tabular}{ll}
\hline Kegiatan & Adaptasi yang dilakukan petani \\
\hline Jenis tanaman & $\begin{array}{l}\text { Ada air menanam sayuran, tidak ada air } \\
\text { menanam tembakau }\end{array}$ \\
Waktu tanam & $\begin{array}{l}\text { Penanaman tembakau menunggu saat } \\
\text { hujan hampir habis }\end{array}$ \\
Cara & - Pemberian mulsa plastik untuk \\
mengolah & mengurangi evaporasi \\
tanah & - Dicangkul, diberi pupuk kandang, \\
Pemberian & diberi mulsa \\
pupuk & Memperbanyak penggunaan kotoran \\
& ayam dan kotoran sapi untuk pupuk \\
& - Setelah tanaman lebih dari 15 hari \\
& baru dipupuk
\end{tabular}

Sumber: Data primer, 2013.

Tabel 6. Pola tanam petani di desa Tlogolele.

\begin{tabular}{lll}
\hline \multicolumn{1}{c}{$\begin{array}{c}\text { Musim hujan } \\
(\mathrm{MH})\end{array}$} & $\begin{array}{l}\text { Musim kering } \\
\text { I (MK I) }\end{array}$ & $\begin{array}{c}\text { Musim kering } \\
\text { II (MK II) }\end{array}$ \\
\hline Cabai merah & Tomat & Tembakau \\
keriting & & \\
Kubis & Brokoli & Kubis \\
Tomat & Sawi & \\
Brokoli & Kubis & \\
\hline
\end{tabular}

Sumber: Data primer, 2013.

hujan dan suhu udara memberikan dampak terhadap peningkatan risiko kegagalan panen, kerusakan hasil panen dan juga meningkatkan serangan OPT. Oleh karena itu, petani menjadi lebih selektif dalam menentukan jenis tanaman yang akan ditanam untuk mengurangi risiko. Adaptasi dilakukan dalam hal penetapan jenis tanaman, pengaturan waktu tanam, cara pengolahan lahan, dan pemberian pupuk (Tabel 5).

Perubahan iklim yang dibarengi dengan musim kering yang panjang, akan direspon petani dengan menanam tanaman sayuran menyesuaikan dengan keadaan, artinya jika ada air menanam sayuran dan melakukan penanaman tembakau di saat musim hujan hampir habis, karena tanaman tembakau sangat peka terhadap kelebihan air baik pada daerah perakaran maupun helaian daunnya. Kondisi kering saat memasuki masa produksi maupun penanganan pasca panen menjadi faktor penentu keberhasilan panen tembakau. Sebaliknya, dari hasil diskusi terfokus, petani memberikan informasi bahwa tanaman sayuran terutama tomat dan cabai sangat sensitif dengan kondisi cuaca saat musim hujan, seperti serangan penyakit patek, thrips dan lalat buah.

Perubahan iklim dianggap memicu peningkatan serangan penyakit patek sehingga risiko kerugian dari serangan OPT ini juga jadi meningkat. Hal ini sejalan dengan pendapat Setiawati dkk. (2011) dan Prathibha dkk. (2013) yang menyatakan bahwa kehilangan potensi hasil cabai akibat penyakit antraknosa bervariasi antara 
25-100\%. Untuk mengurangi risiko gagal panen, petani di Tlogolele mengintegrasikan tembakausayuran (Tabel 6) sesuai dengan penelitian Herawati (2011) di Temanggung. Adaptasi yang tepat pada gilirannya diharapkan mampu menekan kerugian petani akibat perubahan iklim, belajar dari pengalaman petani apel di Malang (Fahriyah dkk., 2011).

\section{KESIMPULAN}

Berdasarkan hasil analisis dapat disimpulkan bahwa petani mengetahui isyu perubahan iklim dan merasakan pengaruhnya terhadap kegiatan budidaya pertanian terutama masalah kekeringan dan serangan organisme pengganggu tanaman. Petani meresponnya melalui adaptasi kegiatan pemilihan jenis tanaman, waktu tanam, cara mengolah tanah, dan pemberian pupuk.

\section{UCAPAN TERIMAKASIH}

Artikel ini merupakan bagian dari penelitian Unggulan Perguruan Tinggi tahun 1 yang dibiayai oleh Koordinasi Perguruan Tinggi Swasta Wilayah VI Kementerian Pendidikan dan Kebudayaan, sesuai dengan Surat Perjanjian Hibah Penelitian No 001/K6/KL/SP/2013 Tanggal 16 Mei 2013

\section{DAFTAR PUSTAKA}

Agbede, T.M., Adekiya, A.O., dan Ogeh, J.S., 2013. Effects of Chromolaena and Tithonia Mulches on Soil Properties, Leaf Nutrient Composition, Growth and Yam Yield. West African Journal of Applied Ecology, 21(1):1529.

Anonim, 2001. Climate Change 2001: Impacts, Adaptation and Vulnerability. Cambridge University Press, Cambridge.

Anonim, 2012. Disaster Risk Reduction and Climate Change Adaptation in the Pacific: An Institutional and Policy Analysis. UNISDR, UNDP, Suva p. 76.

Dhaka B.L., Chayal K., dan Poonia, M.K., 2010. Analysis of Farmers' Perception and Adaptation Strategies to Climate Change. Libyan Agriculture Research Center Journal International, 1(6):388-390.

Fahriyah, Santoso, H., Sabita,S., 2011. Dampak Perubahan Iklim Terhadap Produksi dan Pendapatan Usahatani Apel (Malus sylvestrisl.), Agrise, 19(3):189-194.

Fand, B.B., Kamble, A., dan Kumar, M., 2012. Will Climate Change Pose Serious Threat to Crop Pest Management: A Critical Review?
International Journal of Scientific and Research Publications, 2(11):1-14.

Gbetibouo, G.A., 2008. How Can African Agriculture Adapt to Climate Change? Insights from Ethiopia and South Africa. Understanding Farmers Perceptions and Adaptations to Climate Change and Variability. The Case of the Limpopo Basin, South Africa. IFPRI Research Brief, 15(8):1-2.

Gibson, J.L., Ivancevich, J.M., dan Donnelly, J.H., 1997. Organisasi, Perilaku, Struktur, Proses. Jilid I, Edisi ke 8 (Alih Bahasa: Nunuk Adriani). Binarupa Aksara, Jakarta.

Herawati, T., 2011. Peluang Substitusi Usaha Tembakau dengan Introduksi Sistem Integrasi Domba dan Sayuran di Kabupaten Temanggung. Workshop Nasional Diversifikasi Pangan Daging Ruminansia Kecil 2011. Puslitbang Peternakan, Bogor.

Karuppaiah, V., dan Sujayanad, G.K., 2012. Impact of Climate Change on Population Dynamics of Insect Pests. World Journal of Agricultural Sciences, 8(3):240-246.

Kocmankova, E., Trnka, M., Juroch, J., Dubrovsky, M., Semeradova, D.M., dan Zalud, Z., 2009. Impact of Climate Change on the Occurrence and Activity of Harmful Organisms. Plant Protect Science, 45:S48-S52.

Kurniawati, 2012. Pengetahuan dan Adaptasi Petani Sayuran Terhadap Perubahan Iklim (Studi Kasus: Desa Cibodas, Kecamatan Lembang, Kabupaten Bandung Barat). Tesis, Program Pascasarjana Universitas Padjadjaran, Bandung.

Melviana, Sulistiowati D., dan Soejahmoen M., 2007. Bumi Makin Panas: Ancaman Perubahan Iklim di Indonesia. Kementerian Negara Lingkungan Hidup dan Yayasan Pelangi Indonesia. Jakarta.

Naylor, R., Battisti, D.S., Vimont, D.J., Falcon, W.P., dan Burke, M.B., 2007. Assessing Risks of Climate Variability and Climate Change for Indonesian Rice Agriculture. PNAS 104(19):7752-7757.

Nurmas, A., dan Fitriah, S.P., 2011. Pengaruh Jenis Ppupuk Daun dan Jenis Mulsa terhadap Pertumbuhan dan Produksi Tanaman Bayam Merah (Amaranthus tricolor l.) Varietas BISI. Jurnal Agroteknos, 1(2):89-95.

Owombo, P.T., Koledoye, G.F., Ogunjimi, S.I., Akinola, A.A., Deji, O.F., dan Bolarinwa, O., 2014. Farmer's Adaptation to Climate Change in Ondo State, Nigeria: A Gender Analysis. $J$. of Geography and Regional Planning, 7(2):3035.

Prathibha, V.H., Rao, A.M., Ramesh, R., dan Nanda, C., 2013. Estimation of Fruit Quality 
Parameters in Anthracnose Infected Chilli Fruits. International Journal of Agriculture and Food Science Technology (IJAFST), 4(2):57-60.

Setiawati, W., Sutarya, R., Sumiarta, K., Kamandalu, A., Suryawan, I.B., Latifah, E., dan Luther, G., 2011. Incidence and Severity of Pest and Diseases on Vegetables in Relation to Climate Change (with Emphasis on East Java and Bali). Prosiding Seminar Nasional Perhimpunan Hortikultura Indonesia. Balitsa Lembang p.88-99.
Suwignyo, B., Pratomo, B.W., Supartini, N., Umami, N., dan Suhartanto, B., 2012. Pembungaan dan Produksi Tanaman Jagung di Lahan Pasir. Buana Sains, 12(2):59-62.

Trumble, T.T., dan Butler, C.D., 2009. Climate Change Will Exacerbate California's Insect Pest Problems. California Agriculture, 63(2):73-78.

Wahyono,T., dan Subanar, 2012. Rancang Bangun Sistem "Permadi": Peringatan Dini Serangan Hama Tanaman Padi Berbasis Data Historis Klimatologi. Jurnal Sistem Komputer, 2(1):916. 